\title{
Potential role of autophagy in T-cell survival in polymyositis and dermatomyositis
}

\author{
XIAOMING SHU, FANG CHEN, QINGLIN PENG, XIN LU, XIAOLAN TIAN, YAN WANG and GUOCHUN WANG
}

Department of Rheumatology, China-Japan Friendship Hospital, Chaoyang, Beijing 100029, P.R. China

Received February 24, 2016; Accepted February 10, 2017

DOI: $10.3892 / \mathrm{mmr} .2017 .6693$

\begin{abstract}
Peripheral blood T lymphocytopenia has previously been identified in polymyositis/dermatomyositis (PM/DM) patients. Therefore, the present study aimed to examine the potential role of autophagy in peripheral blood $\mathrm{T}$ cell survival in PM/DM patients. Transmission electron microscopy was used to detect the formation of autophagosomes of peripheral blood cluster of differentiation $(\mathrm{CD}) 3^{+} \mathrm{T}$ cells obtained from 24 patients with PM/DM and 21 healthy controls. Protein and mRNA expression levels of autophagy-related molecules were examined by western blot analysis and reverse transcription-quantitative polymerase chain reaction, respectively. The number of peripheral blood $\mathrm{CD}^{+} \mathrm{T}$ cells decreased significantly in PM/DM patients. The median percentage of apoptosis of $\mathrm{CD}^{+} \mathrm{T}$ cells in $\mathrm{PM} / \mathrm{DM}$ patients was significantly increased compared with healthy controls. Furthermore, the number of autophagosomes and the expression of the autophagy markers microtubule-associated protein 1A/1B-light chain 3 (LC3) and Beclin-1 were significantly reduced in the circulating $\mathrm{CD}^{+} \mathrm{T}$ cells of $\mathrm{PM} / \mathrm{DM}$ patients compared with those of healthy controls. LC3 and Beclin-1 protein levels correlated negatively with apoptosis rates in circulating $\mathrm{CD}^{+} \mathrm{T}$ cells in patients with $\mathrm{PM} / \mathrm{DM}$. $\mathrm{CD}^{+} \mathrm{T}$ cells from PM/DM patients treated with rapamycin increased autophagy and decreased apoptosis compared with untreated cells $(\mathrm{P}<0.05)$. In conclusion, these results suggested that autophagy may serve a potential protective role in the peripheral blood $\mathrm{T}$ cells of patients with PM/DM.
\end{abstract}

\section{Introduction}

Inflammatory myopathies, mainly polymyositis (PM) and dermatomyositis (DM), are a group of autoimmune diseases. Immunohistochemical studies on PM/DM muscle biopsies have demonstrated that $\mathrm{T}$ lymphocytes often infiltrate muscle

Correspondence to: Professor Guochun Wang, Department of Rheumatology, China-Japan Friendship Hospital, 2 YingHua East Road, Chaoyang, Beijing 100029, P.R. China

E-mail: guochunwang@hotmail.com

Key words: polymyositis, dermatomyositis, autophagy, apoptosis fibres $(1,2)$. This abnormal behavior of $\mathrm{T}$ lymphocytes is a characteristic of the pathogenesis of these diseases, although their underlying mechanism remains unclear; in particular, how circulating $\mathrm{T}$ lymphocytes affect inflammatory myopathy.

Our previous study (3) demonstrated that T-cell subsets in peripheral blood were significantly fewer in PM/DM patients. Numerous other studies have additionally indicated that $\mathrm{PM} / \mathrm{DM}$ patients demonstrate significant decreases in their cluster of differentiation (CD) $3^{+} \mathrm{CD} 4^{+} \mathrm{T}$ cell counts (4-8). However, the exact function and mechanism of peripheral blood $\mathrm{T}$ lymphocyte subsets was not investigated in these studies.

T-cell homeostasis is disrupted in autoimmune diseases, including systemic lupus erythmatosus (SLE) and rheumatoid arthritis (RA) (1,9-11). There is growing evidence that T-cell homeostasis is, in part, regulated by the balance between apoptosis and autophagy $(12,13)$. Previous studies have demonstrated that the lymphocytes of patients with autoimmune diseases undergo significantly higher rates of apoptosis compared with healthy controls. It is also widely accepted that increased rates of apoptosis in circulating lymphocytes can trigger an autoimmune reaction due to the release of autoantigens (14).

Autophagy is a highly conserved process by which subcellular components are sequestered and degraded via a lysosomal signalling pathway (15). It has been reported (16) that autophagy serves various functions in the immune system, depending on its cellular contexts or stimuli. On one hand, autophagy serves as a pro-survival mechanism by clearing away intracellular pathogens and antigen presentation, in addition to contributing to lymphocyte homeostasis, thus preventing apoptotic cell death (16). In the absence of the autophagy-related gene (Atg)-5 or Atg-7, CD4 ${ }^{+}$and $\mathrm{CD}^{+} \mathrm{T}$ lymphocytes rapidly undergo apoptosis $(17,18)$. On the other hand, autophagy may additionally mediate cell death $(17,18)$. When stress conditions are too harsh or prolonged, the autophagic machinery is overwhelmed, thus triggering cell death (19).

Previous studies (20-24) have indicated that Atg5 and Atg16/1 polymorphisms are associated with susceptibility SLE, RA and Crohn's disease. Although numerous studies have focused on the role of autophagy and apoptosis in autoimmune diseases, very little information is available specifically about autophagy in PM/DM. Previous examinations of inclusion-body myositis (IBM) and 
PM tissues with mitochondrial pathology have revealed a marked increase in levels of microtubule-associated protein 1A/1B-light chain 3 (LC3)-II, a marker for mature autophagosomes (25). The accumulation of autophagosomes was also a confirmed trend in IBM muscle biopsies (26). Alger et al (27) demonstrated that autophagy markers were upregulated in the muscle fibers of PM/DM patients and in murine myositis. All these studies focused on the role of autophagy in local muscle tissues and recognized autophagy as a non-immune mechanism in idiopathic inflammatory myopathies. However, autophagy is not only a lysosome-mediated catabolic process; it additionally serves a complex function in T cell development, activation, survival and proliferation. Specifically, autophagy helps to regulate cell death and survival in T cells (28). Increased induction of cell death has been reported in Beclin-1-deficient T cells, which correlates with the reduced size of the peripheral $\mathrm{T}$ cell compartment in mice bearing those cells (28).

A thorough understanding of the potential underlying mechanisms of autophagy in T-cells remains to be elucidated. Therefore, the present study aimed to investigate the occurrence of autophagy in $\mathrm{T}$ cells and its potential role in the development of PM/DM to find a novel perspective on this immune mechanism.

\section{Materials and methods}

Subjects. Peripheral blood was obtained from 24 patients with PM/DM (6 PM, 18 DM; 8 male, 16 female; mean age, $37 \pm 13$ years; range, 19-74 years) who were inpatients of the Rheumatology Department of China-Japan Friendship Hospital (Beijing, China). The diagnoses of PM and DM were determined by combining the Bohan and Peter criteria with the European Neuromuscular Centre pathology diagnosis criteria (29-31). The muscle specimens were stained with hematoxylin-eosin, modified Gomori trichrome and a number of enzyme stains, including nicotinamide adenine dinucleotide-tetrazolium reductase, succinic dehydrogenase, adenosine triphosphatase, CD3, CD4, CD8, CD20, CD45RO and major histocompatibility complex class I. All subjects additionally had PM and DM histologically proven by their muscle biopsy results. At the time the serum samples were taken, none of the patients had received immunosuppressive agents during the previous month. These agents included prednisolone, hydroxychloroquine, cyclophosphamide, azathioprine, mycophenolate mofetil and methotrexate. A total of 21 age- and sex-matched healthy individuals were selected to be healthy controls. Complete medical histories were taken and physical examinations were conducted for all patients during their first visit. Clinical and laboratory data, including serum muscular enzyme levels and auto-antibody levels, were obtained at the time serum samples were taken.

Disease activity at the time of diagnosis was assessed using the Myositis Disease Activity Assessment Visual Analogue Scales (MYOACT) established by the International Myositis Assessment and Clinical Studies Group. The study was approved by the ethics committee of the China-Japan Friendship Hospital and all subjects gave written informed consent to participate in the study.
Flow cytometry for analyzing $T$ cell subgroup counts. The amount of $\mathrm{CD}^{+} \mathrm{CD}^{+}{ }^{+} \mathrm{T}$ cells and $\mathrm{CD}^{+} \mathrm{CD}^{+} \mathrm{T}$ cells in peripheral blood was determined by flow cytometry using the following monoclonal antibodies: Anti-CD4-fluorescein isothiocyanate (FITC; catalog co. 557705, BD Biosciences, Franklin Lakes, NJ, USA), anti-CD8-phycoerythrin (PE; catalog no. 555745, BD Biosciences) and anti-CD3-PE-cyanine (catalog no. 555749, BD Biosciences). Serum samples were processed within $6 \mathrm{~h}$ of being obtained. Isotype control-stained cells were also prepared. Data were analyzed using a Cytomics FC500 system (Beckman Coulter, Inc., Brea, CA, USA). In brief, after incubation $1 \times 10^{6}$ cells were suspended with $2.0 \mathrm{ml}$ of a 1:10 dilution of FACS Lysing solution (BD Biosciences) and incubated with anti-CD4-FITC, anti-CD8-PE. and anti-CD3-PE-cyanine antibodies in the dark for $10 \mathrm{~min}$ at room temperature. Cells were centrifuged at $540 \mathrm{x} \mathrm{g}$ for $5 \mathrm{~min}$ at $4^{\circ} \mathrm{C}$, the supernatant was discarded using Pasteur pipettes and the cell pellet was suspended in $50 \mu \mathrm{l}$ buffer solution. Cells were then washed with $2.0 \mathrm{ml}$ PBS containing $0.5 \%$ bovine serum albumin (BSA; Hyclone, GE Healthcare Life Sciences, Chalfont, UK) and $0.09 \%$ sodium azide, vortexed, and centrifuged at $540 \mathrm{x}$ g for $5 \mathrm{~min}$ at $4^{\circ} \mathrm{C}$. Finally, the supernatant was discarded and cells were suspended in $200 \mu \mathrm{l}$ PBS containing $0.5 \%$ BSA. Cells were kept at $4{ }^{\circ} \mathrm{C}$ prior to analysis. After staining, samples were incubated for $15 \mathrm{~min}$ in the dark. Flow cytometric analysis was performed after $2 \mathrm{~h}$ fixation. The data were analyzed with CXP analysis software version 2.1 (Beckman Coulter, Inc., Brea, CA. USA).

$T$ cell isolation and culture. Peripheral blood mononuclear cells (PBMCs) were isolated by Ficoll-Hypaque (Sigma-Aldrich; Merck KGaA, Darmstadt, Germany) density-gradient centrifugation at $400 \mathrm{x}$ g for $30 \mathrm{~min}$ at $37^{\circ} \mathrm{C}$, of samples from the $\mathrm{PM} / \mathrm{DM}$ patients and the healthy controls. Separation of fresh $\mathrm{CD}^{+} \mathrm{T}$ cells from PBMCs was carried out by performing immunomagnetic-based depletion of non-T cells using the Pan T-Cell Isolation kit II (Miltenyi Biotec, Bergisch-Gladbach, Germany). The cell purity was $>95 \%$.

The cells were subsequently stimulated with $10 \mu \mathrm{g} / \mathrm{ml}$ phytohemagglutinin (Sigma-Aldrich; Merck KGaA) and maintained in Roswell Park Memorial Institute 1640 medium (Gibco; Thermo Fisher Scientific, Inc., Waltham, MA, USA), supplemented with $5 \%$ fetal bovine serum (Gibco; Thermo Fisher Scientific, Inc.), 2 mM L-glutamine, $100 \mathrm{U} / \mathrm{ml}$ penicillin and $100 \mu \mathrm{g} / \mathrm{ml}$ streptomycin (Sigma-Aldrich; Merck KGaA). They were subsequently treated with $50 \mathrm{nM}$ rapamycin (Sigma-Aldrich; Merck KGaA) for $48 \mathrm{~h}$.

Transmission electron microscopy. Freshly isolated $\mathrm{CD} 3^{+} \mathrm{T}$ cells were prepared as described above. Briefly, $\mathrm{CD}^{+} \mathrm{T}$ cells were fixed in $3 \%$ glutaraldehyde, stained with $1 \%$ osmium tetroxide, embedded in SeaPlaque agarose (Cambrex Bio Science Rockland, Inc., ME, USA), dehydrated with ethanol and embedded in Epon/Araldite resin. Thin sections were cut to $70 \mathrm{~nm}$, placed on Butvar-coated 200 mesh copper grids, post-stained with $3 \%$ aqueous uranyl acetate and Reynolds lead citrate and subsequently observed under a transmission electron microscope (TEM) using $200 \mathrm{kV}$ power and x15,000 magnification. Autophagic cells were defined as cells with 
Table I. Clinical features of PM/DM patients and healthy controls.

\begin{tabular}{|c|c|c|c|c|}
\hline Clinical feature & PM & $\mathrm{DM}$ & $\mathrm{HC}$ & P-value \\
\hline Patients and healthy controls, no (\%) & $6(25)$ & $18(75)$ & 21 & NA \\
\hline Male:female ratio & $1: 5$ & $1: 1.6$ & $1: 2.2$ & $>0.05$ \\
\hline $\begin{array}{l}\text { Age of onset, mean } \pm \text { standard deviation } \\
\text { (range), yrs }\end{array}$ & $42.2 \pm 14.9(23-58)$ & $44.6 \pm 15.1(18-70)$ & $43.9 \pm 17.2(20-62)$ & $>0.05$ \\
\hline $\begin{array}{l}\text { Duration of disease, mean } \pm \text { standard } \\
\text { deviation (range), months }\end{array}$ & $31.5 \pm 41.1(3-108)$ & $15.2 \pm 18.5(1-72)$ & NA & NA \\
\hline \multicolumn{5}{|l|}{ Clinical characteristics, $\mathrm{n}(\%)$} \\
\hline Fever & $3(50)$ & $6(33)$ & NA & \\
\hline Cutaneous manifestations & $0(0)$ & $18(100)$ & NA & \\
\hline Muscle weakness & $6(100)$ & $18(100)$ & NA & \\
\hline Arthritis & $1(16.7)$ & $5(27.8)$ & NA & \\
\hline Dysphagia & $2(33.3)$ & $5(27.8)$ & NA & \\
\hline Interstitial lung disease & $3(50)$ & $10(55.6)$ & NA & \\
\hline Cardiac involvement & $1(16.7)$ & $0(0)$ & NA & \\
\hline Mechanic's hands & $1(16.7)$ & $3(16.7)$ & NA & \\
\hline $\begin{array}{l}\text { Levels of CK at the time of blood sampling, } \\
\text { mean } \pm \text { standard deviation (IU/l) }\end{array}$ & $1873.8 \pm 4364.5$ & $4151.8 \pm 5304.7$ & NA & $>0.05^{\mathrm{a}}$ \\
\hline Anti-Jo-1 positive & $2(33.3)$ & $4(22.2)$ & NA & $>0.05^{\mathrm{a}}$ \\
\hline ANA positive & $2(33.3)$ & $8(44.4)$ & NA & $>0.05^{\mathrm{a}}$ \\
\hline $\begin{array}{l}\text { MYOACT total disease activity score at the time } \\
\text { of blood sampling, mean } \pm \text { standard deviation }\end{array}$ & $6.3 \pm 1.2$ & $6.7 \pm 1.6$ & NA & $>0.05^{\mathrm{a}}$ \\
\hline White blood cell counts $\left(\times 10^{9} / 1\right)$ & $6.1 \pm 0.7$ & $6.5 \pm 1.1$ & $5.3 \pm 0.8$ & $>0.05^{\mathrm{a}}$ \\
\hline $\mathrm{CD}^{+} \mathrm{T}$ cell count $\left(\mathrm{cell} / \mathrm{mm}^{3}\right)$ & $489.2 \pm 357.8$ & $534.6 \pm 309.2$ & $1532 \pm 1092.4$ & $<0.05^{\mathrm{a}}$ \\
\hline $\mathrm{CD}{ }^{+} \mathrm{CD} 4^{+} \mathrm{T}$ cell count $\left(\mathrm{cell} / \mathrm{mm}^{3}\right)$ & $273.6 \pm 157.1$ & $256.2 \pm 210.0$ & $681.7 \pm 262.5$ & $<0.05$ \\
\hline $\mathrm{CD}^{+}{ }^{+} \mathrm{CD}^{+}{ }^{+} \mathrm{T}$ cell count $\left(\mathrm{cell} / \mathrm{mm}^{3}\right)$ & $210.3 \pm 182.2$ & $229.6 \pm 207.8$ & $437.5 \pm 275.4$ & $<0.05$ \\
\hline
\end{tabular}

PM, polymyositis; DM, dermatomyositis; HC, healthy controls; ILD, interstitial lung disease; CK, creatine kinase; ANA, antinuclear antibody; NA, not assessed; MYOACT, Myositis Disease Activity Assessment Visual Analogue Scales. ${ }^{\text {PMM }}$ and DM vs. healthy control.

$\geq 5$ autophagosomes. The percentage of autophagic cells was quantified by examining $>100$ randomly selected TEM fields by two investigators.

RNA isolation, reverse transcription-polymerase chain reaction (RT-PCR) and RT-quantitative (q)PCR. RNA was isolated from the harvested $C D 3^{+} \mathrm{T}$ cells using TRIzol ${ }^{\circledR}$ reagent (Invitrogen; Thermo Fisher Scientific, Inc.) following the manufacturer's protocol. All the RNA was reverse-transcribed into cDNA (Promega Corporation, Madison, WI, USA). RT-PCR was performed in 96-well plate format using the ABI 7000 Real-Time PCR system (Applied Biosystems; Thermo Fisher Scientific, Inc.). The primers used were as follows: Forward, 5'-GGCTGAGAGACTGGATCAGG-3' and reverse, 5'-CTGCGTCTGGGATAACG-3' for Beclin-1; forward, 5'-GAGAAGCAGCTTCCTGTTCTGG-3' and reverse, 5'-GTGTCCGTTCACCAACAGGAAG-3' for LC3-II; and forward, 5'-GGACTTCGAGCAAGAGATGG-3' and reverse, 5'-TGTGTTGGCGTACAGGTCTTT-3' for $\beta$-actin. mRNA expression levels of $\beta$-actin were measured as an internal reference. The amplification program comprised three stages: An initial $95^{\circ} \mathrm{C}$ Taq activation stage for $10 \mathrm{~min}$, followed by 45 cycles of $95^{\circ} \mathrm{C}$ denaturation for $5 \mathrm{sec}$, and $60^{\circ} \mathrm{C}$ annealing for $35 \mathrm{sec}$. Data were exported into SPSS version 17.0 software (SPSS Inc, Chicago, IL, USA) for further statistical analysis. Gene expression was quantified relative to the expression of endogenous reference genes by calculating the differences in cycle threshold and relative values determined by the $2^{-\Delta \Delta C q}$ method (32).

Western blot analysis. Purified $\mathrm{CD}^{+} \mathrm{T}$ lymphocytes were lysed in radioimmunoprecipitation assay buffer (Thermo Fisher Scientific, Inc.) containing $100 \mathrm{mM}$ Tris-HCl, $\mathrm{pH}$ 8; $150 \mathrm{mM} \mathrm{NaCl} ; 1 \%$ Triton X-100; $1 \mathrm{mM} \mathrm{MgCl}_{2}$; and $25 \mathrm{mM}$ $\mathrm{Na}_{3} \mathrm{VO}_{4}$ and a mixture of protease inhibitors (Thermo Fisher Scientific, Inc.). Protein content was determined by performing a Bradford assay (Thermo Fisher Scientific, Inc.). Lysates were centrifuged at $\sim 14,000 \mathrm{x}$ g for $15 \mathrm{~min}$ to pellet the cell debris. Equal amounts of protein (50 ng) was separated by $10 \%$ SDS-PAGE and transferred onto nitrocellulose membranes. Membranes were blocked at room temperature for $1 \mathrm{~h}$ in a blocking solution containing 5\% skimmed milk in Tris-buffered solution $(50 \mathrm{mM}$ Tris- $\mathrm{HCl}, 150 \mathrm{mM} \mathrm{NaCl}, \mathrm{pH}=7.5)$ and $0.1 \%$ v/v Tween-20. Membranes were incubated at $4^{\circ} \mathrm{C}$ overnight with various primary antibodies, including: rabbit anti-human Beclin polyclonal antibody (1:200; catalog no. PD017; 
Medical \& Biological Laboratories Co., Ltd., Nagoya, Japan); mouse anti-human LC3 monoclonal antibody (1:200; catalog no: SAB1305552; Sigma-Aldrich; Merck KGaA) and anti $\beta$-actin polyclonal antibody (1:500; catalog no.PM053; Medical $\&$ Biological Laboratories Co., Ltd). Membranes were washed and subsequently incubated with peroxidase-conjugated goat anti-mouse IgG (1:500, catalog no. ZB-2305, ZSGB-Bio, Beijing, China), and peroxidase-conjugated goat anti-rabbit IgG (1:500, catalog no. ZB-2301, ZSGB-Bio) for $1 \mathrm{~h}$ at room temperature. Membranes were developed with an Enhanced Chemiluminescence substrate (catalog no. WP20005; Thermo Fisher Scientific, Inc.), and protein bands were captured using a UVP gel imaging system (UVP, Upland, CA, USA). Protein bands were digitized and subjected to densitometry using ImageJ software version 1.48 (National Institutes of Health, Bethesda, MD, USA), on a GS-700 Imaging Densitometer (Bio-Rad Laboratories, Inc., Hercules, CA, USA). $\beta$-actin was used as a loading control to normalize the density of protein bands.

$T$ cell apoptosis analysis. Apoptotic $\mathrm{CD}^{+} \mathrm{T}$ cells were assayed using the Annexin V-FITC kit and propidium iodide (PI) staining according to the manufacturer's protocol (BD Biosciences, Franklin Lakes, NJ, USA). Apoptosis in cells was assessed using the FITC Annexin V Apoptosis Detection kit (BD Biosciences; Annexin V-FITC, PI solution and annexin $\mathrm{V}$ binding buffer). This assay involves staining cells with Annexin V-FITC (a phospholipid-binding protein that binds to disrupted cell membranes) in combination with PI (a vital dye that binds to DNA that penetrates into apoptotic cells). Flow cytometric analysis was performed to determine the percentage of cells that were undergoing apoptosis (Annexin $\mathrm{V}^{+} / \mathrm{PI}^{-}$and Annexin $\mathrm{V}^{+} / \mathrm{PI}^{+}$).

Statistical analysis. For group comparisons associated with binary data, either the $\chi^{2}$ test or Fisher's exact test was used. Comparisons of continuous data were made using the Student's t-tests or the Mann-Whitney U test. Data are expressed as the mean \pm standard deviation and all statistical calculations were performed using SPSS version 17.0 software (SPSS Inc, Chicago, IL, USA). $\mathrm{P}<0.05$ was considered to indicate a statistically significant difference.

\section{Results}

Clinical, serological features and peripheral blood $T$ cell subsets in PM/DM patients. Muscle biopsies were performed on specimens from the $24 \mathrm{PM} / \mathrm{DM}$ patients who were enrolled in the study. Among them, 6 patients had PM and 18 had DM. The clinical characteristics of the patients recruited for this study are summarized in Table I. The male to female ratio was 1:2 among the study subjects. The mean age of onset of PM and DM in these patients was 42.4 and 44.6 years, respectively. In addition, the mean disease duration that the PM and DM patients experienced was 31.5 and 15.2 months, respectively. Disease activity was further assessed using MYOACT tools. The results demonstrated that all PM and DM patients were at the disease activation stage. PM patients had mean MYOACT scores of $6.3 \pm 1.2$, while DM patients had mean scores of $6.7 \pm 1.6$.
Counts of various peripheral blood T-lymphocyte subpopulations were evaluated by flow cytometry. T-cell lymphopenia was identified in PM and DM patients. As demonstrated in Table I, counts of $\mathrm{CD}^{+} \mathrm{T}, \mathrm{CD}^{+} \mathrm{CD}^{+} \mathrm{T}$ and $\mathrm{CD} 3^{+} \mathrm{CD}^{+} \mathrm{T}$ cells in $\mathrm{PM} / \mathrm{DM}$ patients were all significantly reduced compared with healthy controls (all $\mathrm{P}<0.05$ ). Although there were fewer T lymphocytes in PM and DM patients, neutrophils levels were normal in PM and DM patients.

Peripheral blood $T$ cells increased apoptosis rates in $P M / D M$ patients. Considering that peripheral blood $\mathrm{T}$ lymphocytopenia was identified in PM/DM, the first goal of the present study was to investigate whether T lymphocytopenia in peripheral blood from PM/DM patients was caused by T-cell apoptosis. T-cell apoptosis was assessed by flow cytometry. Freshly isolated circulating $\mathrm{CD}^{+} \mathrm{T}$ lymphocytes were analyzed for apoptosis using FITC-conjugated Annexin $\mathrm{V}$ and PI by flow cytometry (Fig. 1A). As demonstrated in Fig. 1B, the median percentage of apoptotic $\mathrm{CD}^{+} \mathrm{T}$ cells in patients with PM was $9.95 \pm 0.83 \%$, whereas it was $14.3 \pm 0.88 \%$ in patients with DM. These were significantly increased compared with the healthy controls $(5.83 \pm 0.45 \%$; $\mathrm{P}<0.001)$. In addition, the percentage of apoptotic $\mathrm{CD}^{+} \mathrm{T}$ cells in DM patients was significantly increased compared with PM patients $(\mathrm{P}<0.05)$. Following this, the correlation between apoptotic rates and $\mathrm{CD}^{+} \mathrm{T}$ lymphocytes was examined. A significant negative correlation between the higher rates of $\mathrm{CD}^{+} \mathrm{T}$ lymphocyte apoptosis and counts of $\mathrm{CD}^{+}$ $\mathrm{T}$ cells in $\mathrm{PM} / \mathrm{DM}$ patients was identified $(\mathrm{P}<0.05$; Fig. $1 \mathrm{C}$ and D). As was expected, increased rates of apoptosis led to reduced T-cell counts.

Decreased autophagy levels in freshly isolated $T$ cells from PM/DM patients. According to data from a previous study (28), autophagy additionally contributes to the maintenance of lymphocyte homeostasis. Therefore, to study how the autophagy machinery in peripheral $\mathrm{CD}^{+} \mathrm{T}$ lymphocytes determines cell survival in PM/DM patients, these cells were examined for the presence of autophagosomes using TEM, and for the presence of the autophagosomal markers LC3-II and Beclin-1 by western blot analysis and RT-qPCR. Autophagosomes were imaged in healthy control (Fig. 2A) and DM (Fig. 2B) patients. In addition, TEM revealed fewer numbers of autophagosomes in PM/DM patients than in healthy controls $(\mathrm{P}<0.05$; Fig. $2 \mathrm{C})$. To examine autophagic activity in $\mathrm{PM} / \mathrm{DM}$ patients, Beclin-1 mRNA and protein expression levels were examined in addition to LC3 mRNA and protein expression, using RT-qPCR and western blot analysis. LC3 mRNA (Fig. 2D) and protein (Fig. 2E) expression levels were significantly reduced in $\mathrm{PM} / \mathrm{DM}$ patients compared with healthy controls $(\mathrm{P}<0.01$ and $\mathrm{P}<0.001$, respectively). Beclin-1 mRNA (Fig. 2F) and protein (Fig. 2G) expression levels were additionally reduced in $\mathrm{PM} / \mathrm{DM}$ patients compared with healthy controls $(\mathrm{P}<0.01$ and $\mathrm{P}<0.001$, respectively). Representative images of mRNA and protein expression levels of LC3 and Beclin-1 are presented in Fig. $2 \mathrm{H}$ and I, respectively. Together, these results indicated that autophagy rates are reduced in PM/DM and that autophagy may be involved in the pathogenesis of $\mathrm{PM} / \mathrm{DM}$. 
A

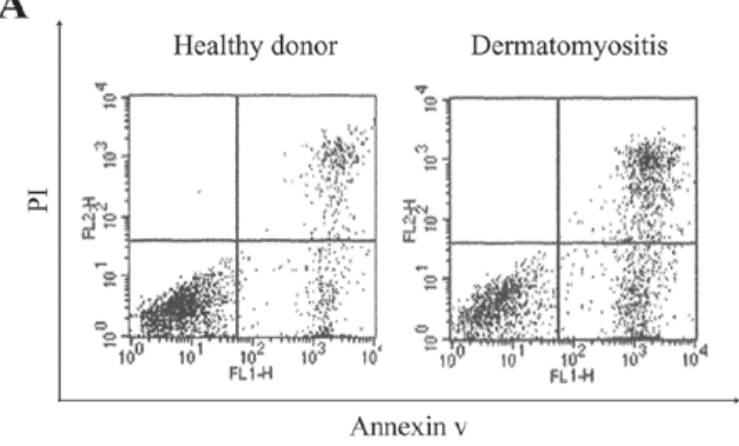

C

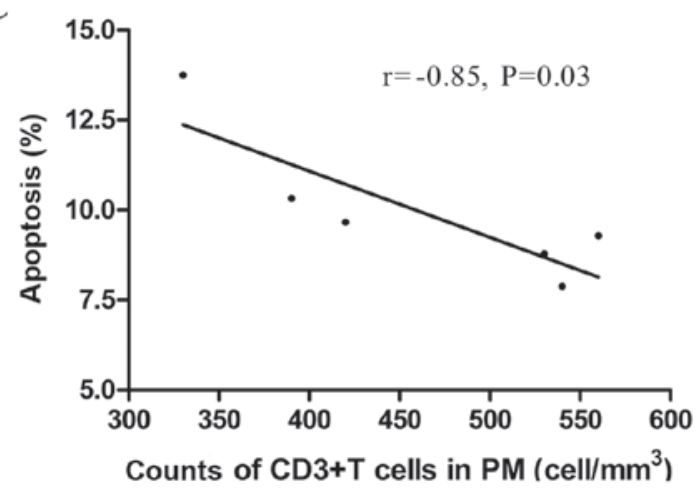

B

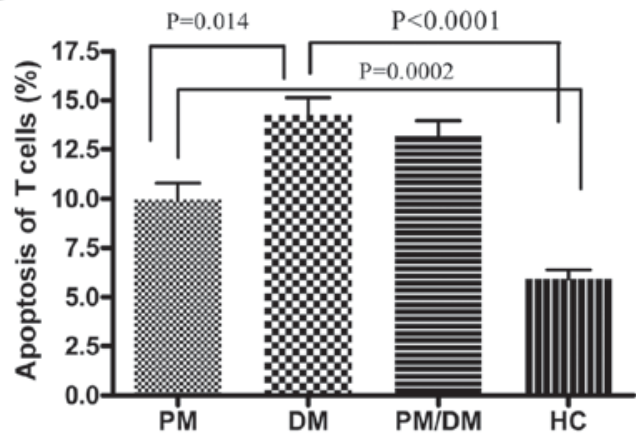

D

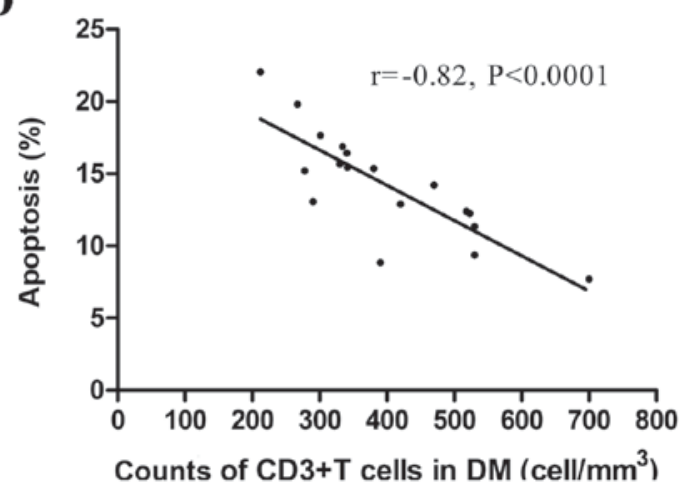

Figure 1. Apoptosis detection in freshly isolated peripheral blood T cells from patients with PM/DM and from healthy controls. (A) Flow cytometry analysis of lymphocyte apoptosis. Representative dot plots of flow cytometry analysis (PI on y-axis vs. AV on x-axis). Numbers reported for AV single-positive cells and for AV/PI double-positive cells represent percentages of apoptotic lymphocytes in the bottom-right quadrants. (B) The median percentage of apoptotic CD $3^{+}$ T lymphocytes in peripheral blood was obtained from 9 patients with PM, 18 patients with DM and 21 healthy controls. Percentages of apoptotic T cells in PM $(9.95 \pm 0.83 \%)$ and $\mathrm{DM}(14.3 \pm 0.88 \%)$ were significantly increased compared with $\mathrm{HCs}(5.83 \pm 0.45 \%)$. Data are presented as the mean \pm standard deviation. There was a significant negative correlation between increased apoptosis rates of $\mathrm{CD}^{+} \mathrm{T}$ lymphocytes and counts of $\mathrm{CD} 3^{+} \mathrm{T}$ cells in (C) $\mathrm{PM}$ and (D) DM patients $(\mathrm{r}=-0.85, \mathrm{P}=0.03 ; \mathrm{r}=-0.82, \mathrm{P}<0.0001$, respectively). PM, polymyositis; DM, dermatomyositis; PI, propidium iodide; AV, Annexin V; HC, healthy controls; CD, cluster of differentiation.

To understand the role of autophagy in peripheral $\mathrm{CD}^{+} \mathrm{T}$ cell survival, the correlation between LC3-II or Beclin-1 levels and apoptosis rates in peripheral $\mathrm{CD}^{+} \mathrm{T}$ cells in $\mathrm{PM} / \mathrm{DM}$ patients was analyzed. As presented in Fig. 3A, there was a significant negative correlation between LC3-II protein levels and apoptosis rates in circulating $\mathrm{CD}^{+} \mathrm{T}$ cells in $\mathrm{PM} / \mathrm{DM}$ patients $(\mathrm{r}=-0.7, \mathrm{P}=0.0001)$. There was additionally a significant negative correlation between apoptosis rates and Beclin-1 protein levels in peripheral blood $\mathrm{CD}^{+} \mathrm{T}$ cells in $\mathrm{PM} / \mathrm{DM}$ patients $(\mathrm{r}=-0.58, \mathrm{P}=0.003$; Fig. $3 \mathrm{~B})$. This result may indirectly suggest that decreased autophagy activity contributes to the apoptosis of peripheral blood $\mathrm{T}$ cells.

Autophagy prevents $C D 3^{+} T$ cell apoptosis in PM/DM patients. To explore whether autophagy has a cytoprotective effect on peripheral blood T cells in PM/DM patients, the effect of autophagy on T-cell survival in vitro was next examined. First, $\mathrm{CD}^{+} \mathrm{T}$ cells from $10 \mathrm{DM}$ patients were treated with the autophagy inducer rapamycin for $48 \mathrm{~h}$. Following this treatment, $\mathrm{LC} 3$-II protein levels in $\mathrm{CD}^{+} \mathrm{T}$ cells of $\mathrm{DM}$ patients were significantly increased compared with untreated $\mathrm{CD}^{+} \mathrm{T}$ cells (0.54 \pm 0.17 vs. $0.18 \pm 0.08$ P $<0.05$, Fig. 4 A). Secondly, LC3-II protein levels in the $\mathrm{CD}^{+} \mathrm{T}$ cells of healthy controls were detected. No significant difference was observed in LC3-II protein expression levels between $\mathrm{CD}^{+} \mathrm{T}$ cells treated with rapamycin and those not treated with rapamycin $(0.52 \pm 0.28$ vs. $0.43 \pm 0.23 ; \mathrm{P}>0.05$ ). Furthermore, no significant difference was observed in LC3-II levels between the rapamycin-treated $\mathrm{T}$ cells of DM patients and those of healthy controls (Fig. 4A; $\mathrm{P}>0.05$ ).

The apoptosis rates of $\mathrm{CD}^{+} \mathrm{T}$ cells from $\mathrm{PM} / \mathrm{DM}$ patients and healthy controls following rapamycin treatment were additionally assessed. The results demonstrated that all $\mathrm{CD}^{+}$ $\mathrm{T}$ cells had decreased apoptosis rates following treatment by rapamycin, regardless of donors. Apoptosis rates in PM/DM patients treated with rapamycin were significantly reduced compared with untreated patients $(7.15 \pm 0.21 \%$ vs. $13.7 \pm 0.33 \%$; $\mathrm{P}<0.05$; Fig. 4B). Apoptosis rates in rapamycin-treated healthy controls were slightly reduced compared with untreated healthy controls; however, this was not significant $(4.98 \pm 0.14 \%$ vs. $5.56 \pm 0.27 \%$; P>0.05; Fig. 4B).

Similar results were observed in PM patients (data not shown). All these results implied that autophagy activation could lead to cytoprotection in PM/DM patients.

\section{Discussion}

To the best of our knowledge, the present study addressed for the first time the autophagic behaviour of peripheral blood $\mathrm{T}$ lymphocytes in PM/DM patients. The results suggested that decreased autophagy and increased apoptosis in peripheral blood T cells from PM/DM patients may be involved in the 

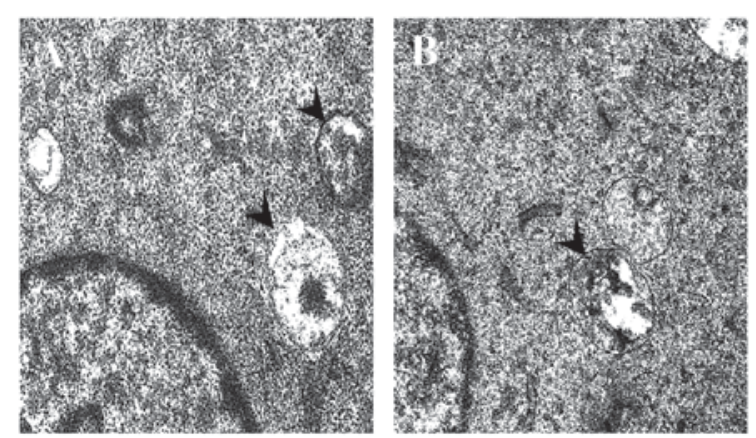

$\mathbf{D}$

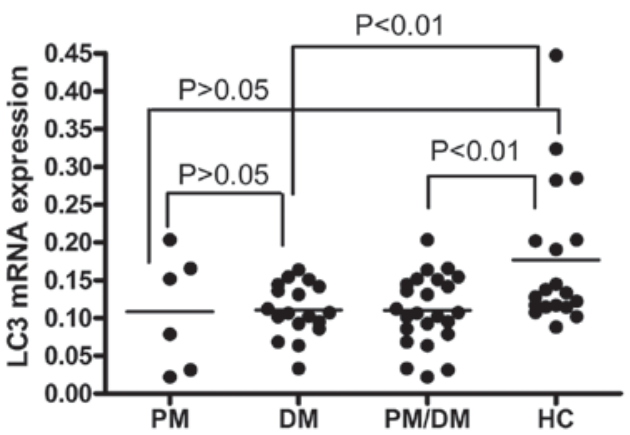

$\mathbf{F}$

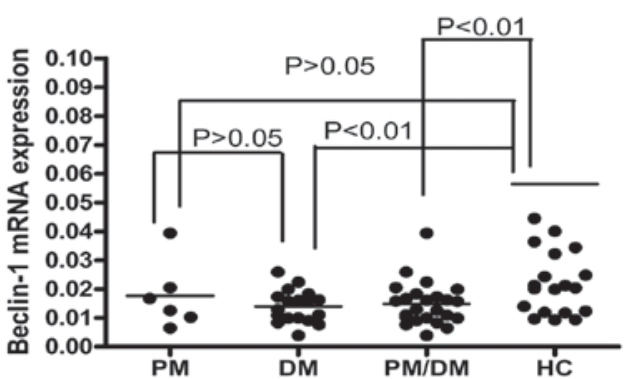

$\mathbf{H}$

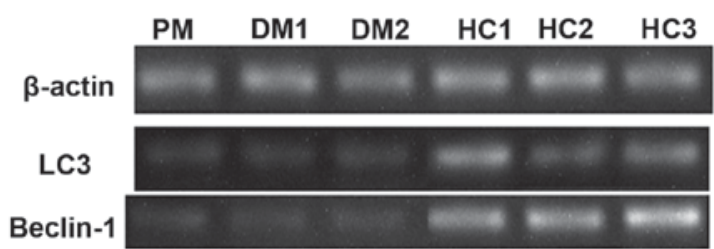

C

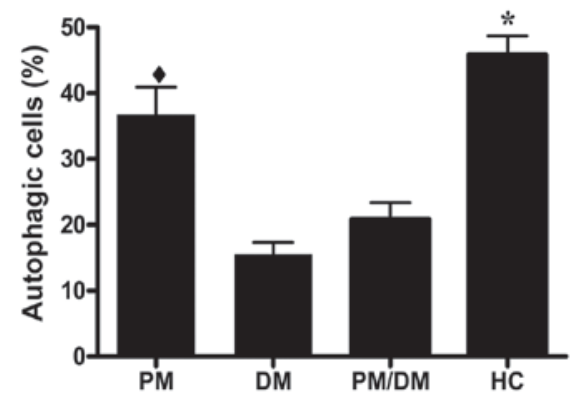

$\mathbf{E}$

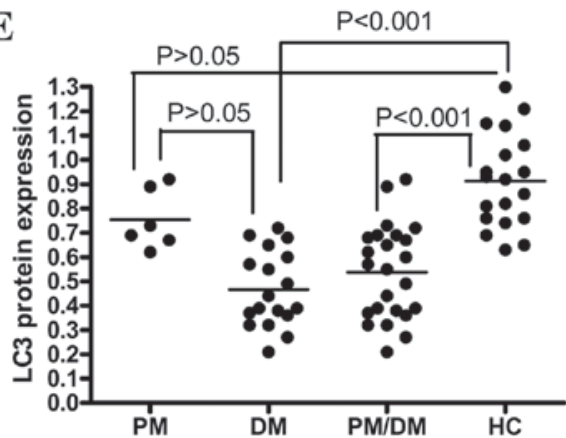

G

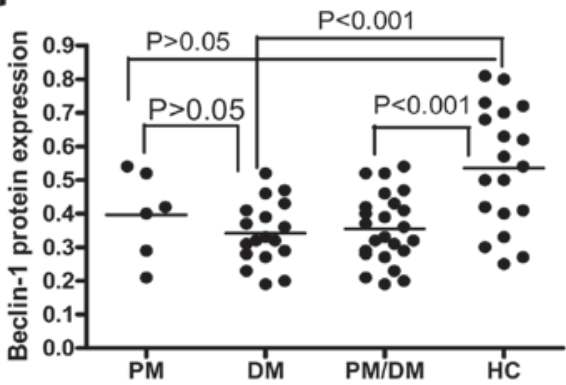

I

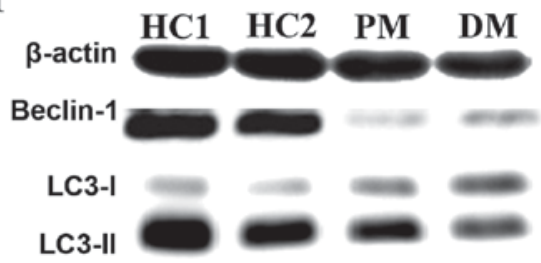

Figure 2. Autophagy levels in freshly isolated $\mathrm{CD}^{+} \mathrm{T}$ cells from PM/DM patients. TEM images are representative samples from (A) healthy control and (B) DM patients. A total of 10 fields in each sample were randomly examined. Arrows denote autophagosomes. (C) Quantitative analysis of number of autophagosomes detected by TEM with $200 \mathrm{kV}$ power and x15,000 magnification. Data are expressed as the mean \pm standard deviation. "P $<0.0001$ vs. DM andPM/DM groups; 'P $>0.05$ vs. PM and HC patients. RT-qPCR and western blot analysis were performed to evaluate the expression of autophagy-specific markers LC3-II and Beclin-1. Dot plots are representative of independent experiments performed on the $\mathrm{CD} 3^{+} \mathrm{T}$ cells of 21 healthy donors, of $6 \mathrm{PM}$ patients and of $18 \mathrm{DM}$ patients. $\mathrm{LC} 3$ (D) mRNA and (E) protein expression levels. Beclin-1 (F) mRNA and (G) protein expression levels. Representative (H) RT-qPCR and (I) western blot images of Beclin-1 and LC3mRNA and protein expression levels, respectively. $\beta$-actin served as an internal control. PM, polymyositis; DM, dermatomyositis; TEM, transmission electron microscope; HC, healthy controls; RT-qPCR, reverse transcription-quantitative polymerase chain reaction; LC3, microtubule-associated protein 1A/1B-light chain 3; CD, cluster of differentiation.

pathogenesis of inflammatory myopathies. The results from the present study also suggested that decreased autophagy may serve a role in the increased apoptosis of peripheral blood $\mathrm{T}$ cells. Taken together, these findings clarify the potential role of autophagy in preventing inflammatory myopathies by regulating peripheral T-cell survival.

The pathogenesis of inflammatory myopathy is complex. Previous studies have mainly focused on the muscular microenvironment (33-35); research on peripheral blood immune cells is lacking. T-cell homeostasis is disrupted in autoimmune diseases, including SLE and RA $(36,37)$. Recent immunohistochemical studies on muscle biopsies from our laboratory and others have also demonstrated that T lymphocytes often infiltrate muscle fiber in PM/DM $(38,39)$. T-cell abnormalities have additionally been observed in murine models (40). However, only a small number of studies have 
A

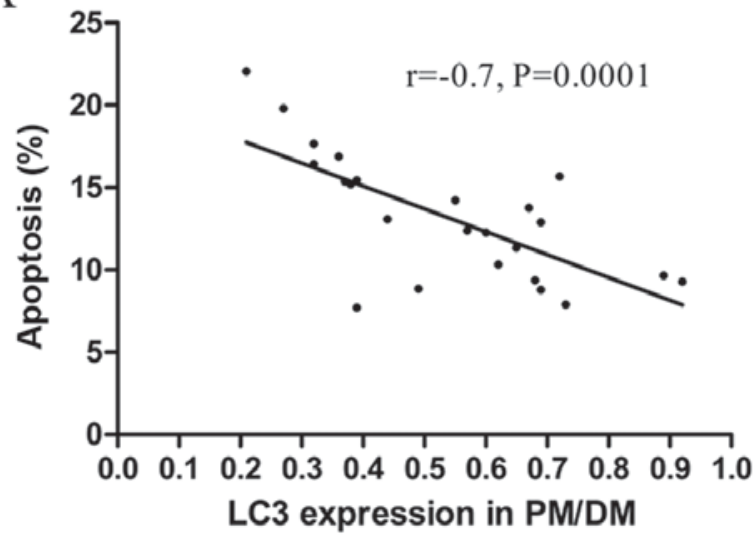

$\mathrm{B}$

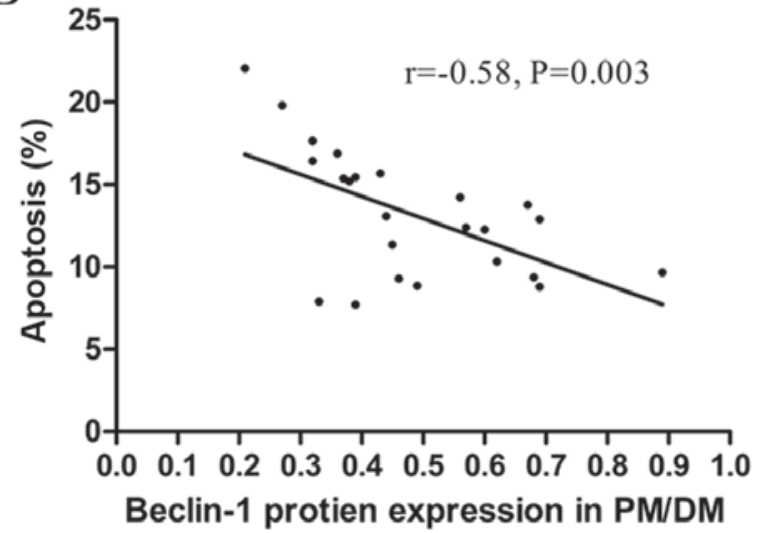

Figure 3. Correlation between apoptosis and autophagy in patients with PM/DM. Linear regression analysis of correlation between apoptosis and (A) LC3-II or (B) Beclin-1 protein expression in T cells from patients with PM/DM. PM, polymyositis; DM, dermatomyositis; LC3, microtubule-associated protein 1A/1B-light chain 3.

A

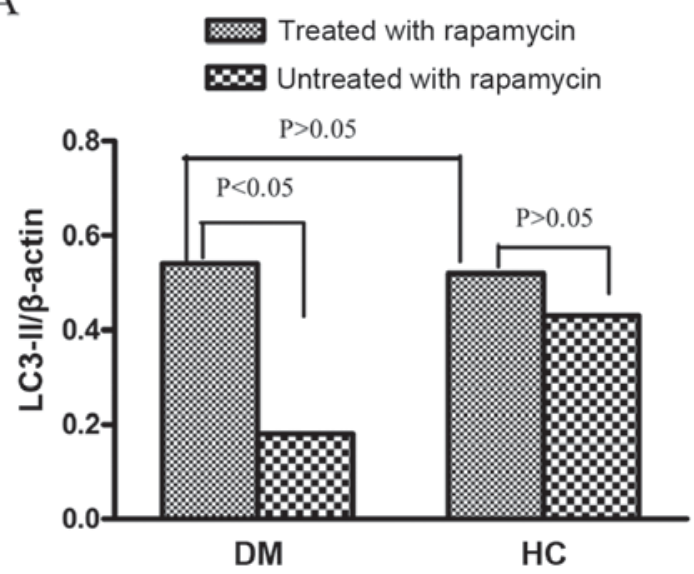

$\mathrm{B}$

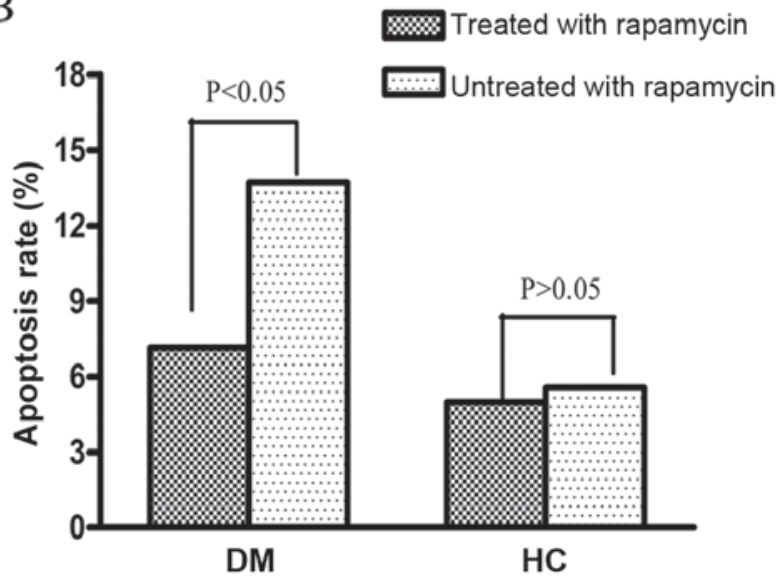

Figure 4. Effects of rapamycin on peripheral blood $\mathrm{CD} 3^{+} \mathrm{T}$ cell survival and autophagy activity in PM/DM patients. Increasing autophagy via rapamycin treatment protects $\mathrm{CD}^{+} \mathrm{T}$ cells from injury in patients with PM/DM. (A) LC3-II protein levels in the rapamycin-treated CD3 ${ }^{+} \mathrm{T}$ cells of DM patients were significantly increased compared with untreated cells $(0.54 \pm 0.17$ vs. $0.18 \pm 0.08 ; \mathrm{P}<0.001)$ although no significant difference was observed in LC3-II protein levels in the rapamycin-treated $\mathrm{CD}^{+} \mathrm{T}$ cells of healthy controls compared with untreated T cells $(0.52 \pm 0.28$ vs $0.43 \pm 0.23$; $\mathrm{P}>0.05)$. Furthermore, no significant difference was observed between rapamycin-treated DM patients and rapamycin-treated healthy controls (P>0.05). (B) Similarly, apoptosis rates in patients treated with rapamycin were redcued compared with untreated patients $(7.15 \pm 0.21 \%$ vs. $13.7 \pm 0.33 \%$; $<<0.05)$. Apoptosis rates in rapamycin-treated healthy controls were only slightly reduced compared with untreated healthy controls (4.98 $\pm 0.14 \%$ vs. 5.56 $\pm 0.27 \%$; P>0.05). PM, polymyositis; DM, dermatomyositis; LC3, microtubule-associated protein 1A/1B-light chain 3; CD, cluster of differentiation.

investigated the characteristics and pathogenesis of PM/DM in peripheral blood T lymphocytes. Data from our previous study (3) and the present study demonstrated that circulating T lymphopenia occurs in PM/DM patients. The findings of the present study are consistent with a recent study that additionally identified a high frequency of lymphopenia in PM/DM (41).

A potential reason for this lymphopenia in PM/DM is increased apoptosis of peripheral $\mathrm{T}$ cells. The results of the present study demonstrated that apoptosis rates were significantly increased in PM/DM patients compared with healthy controls. Furthermore, PM/DM patients possessed lymphopenia that inversely correlated with T-cell apoptosis, suggesting a cause and effect association. Similar findings were observed in SLE patients: Dhir et al (42) confirmed an increased rate of apoptosis in the T-lymphocytes of SLE patients, and identified that peripheral blood $\mathrm{T}$ lymphopenia had a direct negative correlation with T-cell apoptosis rates.
Numerous mechanisms have been proposed to explain the increased apoptosis rates of $\mathrm{T}$ cells in autoimmune diseases. Among these, the importance of autophagy in the maintenance of T-lymphocytes homeostasis has been recognized $(15,16)$. Autophagy has been identified to be deregulated in $\mathrm{CD}^{+} \mathrm{T}$ cells from lupus-prone mice (43). T lymphocytes from SLE patients were resistant to autophagic induction and exhibited an upregulation of genes that inhibit autophagy (44). This resistance and inhibition may explain the increased apoptosis rates detected in SLE patients $(44,45)$. In agreement with these results, the present study demonstrated that autophagy decreased and apoptosis increased in circulating $\mathrm{CD}^{+} \mathrm{T}$ cells. Increased induction of cell death has been reported (28) in Beclin-1-deficient T cells, which correlated with the reduced size of the peripheral T- cell compartment in mice bearing those cells. The present study demonstrated that circulating $\mathrm{CD}^{+}$ T-cell counts in PM/DM patients were reduced compared with 
healthy controls, which may result from decreased autophagy. $\mathrm{CD}^{+} \mathrm{T}$ cells from PM/DM patients treated with rapamycin had even further reduced apoptosis rates compared with similar but untreated $\mathrm{T}$ cells $(\mathrm{P}<0.05)$, while apoptosis rates were similarly decreased in treated and untreated $\mathrm{CD}^{+} \mathrm{T}$ cells from healthy controls $(\mathrm{P}>0.05)$. These findings indicated that abnormal autophagy may result in increased apoptosis of peripheral blood T cells in PM/DM.

Links between autophagy and apoptosis have been observed in various eukaryotic cells (46). Atg $7^{-/-}$T lymphocytes upregulate the expression of Bcl-2 (47). Beclin-1-deficient T lymphocytes exhibit markedly increased levels of pro-apoptotic pro-caspase-8, pro-caspase-3 and Bcl-2-like protein 11 (48). However, the exact mechanism by which autophagy regulates apoptosis in Tlymphocytes remains to be elucidated. Numerous mechanisms have been proposed to explain the involvement of autophagy in the regulation of T cell survival (49). Altered degradation of mitochondria with increased production of reactive oxygen species (ROS) has been observed in autophagy-deficient T cells (47). An uncontrolled burst in the generation of ROS following T-cell receptor engagement may account for the increased rates of cell death observed in activated autophagy-deficient T cells. Endoplasmic reticulum stability is additionally dependent on autophagy in $\mathrm{T}$ cells, and autophagy-deficient $\mathrm{T}$ cells demonstrate functional defects in calcium signaling, a potential consequence of altered mobilization from the intracellular calcium stores of the endoplasmic reticulum (28).

In conclusion, the present study indicated that autophagy may serve a potential cy toprotective role in PM/DM, potentially via inhibition of apoptosis in circulating $\mathrm{CD} 3^{+} \mathrm{T}$ cells. These data suggested that autophagy may not only be cytoprotective in preventing inflammatory myopathies, but additionally serve a pivotal role in apoptosis regulation. Further studies are required to investigate the underlying molecular mechanisms and interactions between abnormal autophagy and apoptosis in the development of PM/DM.

\section{Acknowledgements}

The authors thank all the patients and healthy participants in the present study, which was funded by the General Program of the National Natural Science Foundation of China (grant nos. 81172860 and 81571603), the Major Research Plan of the National Natural Science of China (grant no. 91542121), the Youth Program of the National Natural Science Foundation of China (grant no. 81401363) and the Capital Health Research and Development of Special Program (grant no. 2014-4-4062).

\section{References}

1. Malmström V, Venalis $\mathrm{P}$ and Albrecht $\mathrm{I}$ : $\mathrm{T}$ cells in myositis. Arthritis Res Ther 14: 230, 2012.

2. Venalis $P$ and Lundberg IE: Immune mechanisms in polymyositis and dermatomyositis and potential targets for therapy. Rheumatology (Oxford) 53: 397-405, 2014.

3. Wang DX, Lu X, Zu N, Lin B, Wang LY, Shu XM, Ma L and Wang GC: Clinical significance of peripheral blood lymphocyte subsets in patients with polymyositis and dermatomyositis. Clin Rheumatol 31: 1691-1697, 2012.

4. Ishii W, Matsuda M, Shimojima Y, Itoh S, Sumida T and Ikeda S: Flow cytometric analysis of lymphocyte subpopulations and $\mathrm{TH} 1 / \mathrm{TH} 2$ balance in patients with polymyositis and dermatomyositis. Intern Med 47: 1593-1599, 2008.
5. Aleksza M, Szegedi A, Antal-Szalmás P, Irinyi B, Gergely L, Ponyi A, Hunyadi J, Sipka S, Zeher M, Szegedi G and Dankó K: Altered cytokine expression of peripheral blood lymphocytes in polymyositis and dermatomyositis. Ann Rheum Dis 64: 1485-1489, 2005.

6. Viguier M, Fouéré S, de la Salmonière P, Rabian C, Lebbe C, Dubertret L, Morel P and Bachelez H: Peripheral blood lymphocyte subset counts in patients with dermatomyositis: Clinical correlations and changes following therapy. Medicine (Baltimore) 82: 82-86, 2003.

7. Eisenstein DM, O'Gorman MR and Pachman LM: Correlations between change in disease activity and changes in peripheral blood lymphocyte subsets in patients with juvenile dermatomyositis. J Rheumatol 24: 1830-1832, 1997.

8. Ishida T, Matsumoto Y, Ohashi M and Sasaki R: Analysis of lymphocyte subpopulations in peripheral blood in adult and juvenile cases of dermatomyositis. J Dermatol 20: 30-34, 1993.

9. Cope AP, Schulze-Koops H and Aringer M: The central role of T cells in rheumatoid arthritis. Clin Exp Rhuematol 25 (5 Suppl 46): S4-S11, 2007.

10. La Cava A: Lupus and T cells. Lupus 18: 196-201, 2009.

11. Wehrens EJ, Prakken BJ and van Wijk F: T cells out of control-impaired immune regulation in the inflame joint. Nat Rev Rheumatol 9: 34-42, 2013.

12. Klionsky DJ and Emr SD: Autophagy as a regulated pathway of cellular degradation. Science 290: 1717-1721, 2000.

13. Pope RM: Apoptosis as a therapeutic tool in rheumatoid arthritis. Nat Rev Immunol 2: 527-535, 2002.

14. Citro A, Barnaba V and Martini H: From $\mathrm{T}$ cell apoptosis to chronic immune activation in inflammatory diseases. Int Arch Allergy Immunol 164: 140-146, 2014.

15. Choi AM, Ryter SW and Levine B: Autophagy in human health and disease. N Engl J Med 368: 651-662, 2013.

16. Lleo A, Invernizzi P, Selmi C, Coppel RL, Alpini G, Podda M, Mackay IR and Gershwin ME: Autophagy: Highlighting a novel player in the autoimmunity scenario. J Autoimmun 29: 61-68, 2007.

17. Bhattacharya A and Eissa NT: Autophagy and autoimmunity crosstalks. Front Immunol 4: 88, 2013.

18. Kuballa P, Nolte WM, Castoreno AB and Xavier RJ: Autophagy and the immune system. Annu Rev Immunol 30: 611-646, 2012.

19. Ma Y, Galluzzi L, Zitvogel L and Kroemer G: Autohagy and cellular immune responses. Immunity 39: 211-227, 2013.

20. Han JW, Zheng HF, Cui Y, Sun LD, Ye DQ, Hu Z, Xu JH, Cai ZM, Huang W, Zhao GP, et al: Genome-wide association study in a Chinese Han population identifies nine new susceptibility loci for systemic lupus erythematosus. Nat Genet 41: 1234-1237, 2009.

21. International Consortium for Systemic Lupus Erythematosus Genetics (SLEGEN), Harley JB, Alarcón-Riquelme ME, Criswell LA, Jacob CO, Kimberly RP, Moser KL, Tsao BP, Vyse TJ, Langefeld CD, et al: Genome-wide association scan in women with systemic lupus erythematosus identifies susceptibility variants in ITGAM, PXK, KIAA1542 and other loci. Nat Genet 40: 204-210, 2008.

22. Zhou XJ, Lu XL, Lv JC, Yang HZ, Qin LX, Zhao MH, Su Y, Li ZG and Zhang H: Genetic association of PRDM1-ATG5 intergenic region and autophagy with systemic lupus erythematosus in a Chinese population. Ann Rheum Dis 70: 1330-1337, 2011.

23. Raychaudhuri S, Thomson BP, Remmers EF, Eyre S, Hinks A, Guiducci C, Catanese JJ, Xie G, Stahl EA, Chen R, et al: Genetic variants at $\mathrm{CD} 28, \mathrm{PRDM} 1$ and CD2/CD58 are associated with rheumatoid arthritis risk. Nat Genet 41: 1313-1318, 2009.

24. Parkes M, Barrett JC, Prescott NJ, Tremelling M, Anderson CA, Fisher SA, Roberts RG, Nimmo ER, Cummings FR, Soars D, et al: Sequence variants in the autophagy gene IRGM and multiple other replicating loci contribute to Crohn's disease susceptibility. Nat Genet 39: 830-832, 2007.

25. Temiz P, Weihl CC and Pestronk A: Inflammatory myopathies with mitochondrial pathology and protein aggregates. J Neurol Sci 278: 25-29, 2009.

26. Nogalska A, D'Agostino C, Terracciano C, Engel WK and Askanas V: Impaired autophagy in sporadic inclusion-body myositis and in endoplasmic reticulum stress-provoked cultured human muscle fibers. Am J Pathol 177: 1377-1387, 2010.

27. Alger HM, Raben N, Pistilli E, Francia DL, Rawat R, Getnet D, Ghimbovschi S, Chen YW, Lundberg IE and Nagaraju K: The role of TRAIL in mediating autophagy in myositis skeletal muscle: A potential nonimmune mechanism of muscle damage. Arthritis Rheum 63: 3448-3457, 2011. 
28. Jia W and He YW: Temporal regulation of intracellular organelle homeostasis in T lymphocytes by autophagy. J Immunol 186: 5313-5322, 2011

29. Bohan A and Peter JB: Polymyositis and dermatomyositis (first of two parts). N Engl J Med 292: 344-347, 1975.

30. Bohan A and Peter JB: Polymyositis and dermatomyositis (second of two parts). N Engl J Med 292: 403-407, 1975.

31. Hoogendijk JE, Amato AA, Lecky BR, Choy EH, Lundberg IE, Rose MR, Vencovsky J, de Visser M and Hughes RA: 119th ENMC international workshop: Trial design in adult idiopathic inflammatory myopathies, with the exception of inclusion body myositis, 10-12 October 2003, Naarden, The Netherlands Neuromuscul Disord 14: 337-345, 2004.

32. Livak KJ and Schmittgen TD: Analysis of relative gene expression data using real-time quantitative PCR and the 2(-Delta Delta C(T)) Method. Methods 25: 402-408, 2001.

33. Findlay AR, Goyal NA and Mozaffar T: An overview of polymyositis and dermatomyositis. Muscle Nerve 51: 638-656, 2015.

34. Mammen AL: Autoimmune myopathies: Autoantibodies, phenotypes and pathogenesis. Nat Rev Neurol 7: 343-354, 2011.

35. Amato AA and Greenberg SA: Inflammatory myopathies. Continuum (Minneap Minn) 19 (6 Muscle Disease): 1615-1633, 2013.

36. Suárez-Fueyo A, Bradley SJ and Tsokos GC: T cells in systemic lupus erythematosus. Curr Opin Immunol 43: 32-38, 2016.

37. Wu DJ and Adamopoulos IE: Autophagy and autoimmunity. Clin Immunol 176: 55-62, 2017.

38. Peng QL, Zhang YL, Shu XM, Yang HB, Zhang L, Chen F, Lu X and Wang GC: Elevated serum levels of soluble CD163 in polymyositis and dermatomyositis: Associated with macrophage infiltration in muscle tissue. J Rheumatol 42 : 979-987, 2015.

39. Fasth AE, Dastmalchi M, Rahbar A, Salomonsson S, Pandya JM, Lindroos E, Nennesmo I, Malmberg KJ, Söderberg-Nauclér C, Trollmo C, et al: $\mathrm{T}$ cell infiltrates in the muscles of patients with dermatomyositis and polymyositis are dominated by CD28null $\mathrm{T}$ cells. J Immunol 183: 4792-4799, 2009.
40. Sugihara T, Sekine C, Nakae T, Kohyama K, Harigai M, Iwakura Y, Matsumoto Y, Miyasaka N and Kohsaka H: A new murine model to define the critical pathologic and therapeutic mediators of polymyositis. Arthritis Rheum 56: 1304-1314, 2007.

41. Espinosa-Ortega F, Gómez-Martin D, Santana-De Anda K, Romo-Tena J, Villaseñor-Ovies $\mathrm{P}$ and Alcocer-Varela J: Quantitative T cell subsets profile in peripheral blood from patients with idiopathic inflammatory myopathies: Tilting the balance towards proinflammatory and pro-apoptotic subsets. Clin Exp Immunol 179: 520-528, 2015.

42. Dhir V, Singh AP, Aggarwal A, Naik S and Misra R: Increased T-lymphocyte apoptosis in lupus correlates with disease activity and may be responsible for reduced T-cell frequency: A cross-sectional and longitudinal study. Lupus 18: 785-791, 2009.

43. Gros F, Arnold J, Page N, Décossas M, Korganow AS, Martin T and Muller S: Macroautophagy is deregulated in murine and human lupus T lymphocytes. Autophagy 8: 1113-1123, 2012.

44. Alessandri C, Barbati C, Vacirca D, Piscopo P, Confaloni A, Sanchez M, Maselli A, Colasanti T, Conti F, Truglia S, et al: T lymphocytes from patients with systemic lupus eythematosus are resistant to induction of autophagy. FASEB J 26: 4722-4732, 2012.

45. Emlen W, Niebur J and Kadera R: Accelerated in vitro apoptosis of lymphocytes from patients with systemic lupus erythematosus. J Immunol 152: 3685-3692, 1994.

46. Thorburn A: Apoptosis and autophagy: regulatory connections between two supposedly different processes. Apoptosis 13: 1-9, 2008.

47. Pua HH, Guo J, Komatsu M and He YW: Autophagy is essential for mitochondrial clearance in mature $\mathrm{T}$ lymphocytes. J Immunol 182: 4046-4055, 2009.

48. Kovacs JR, Li C, Yang Q, Li G, Garcia IG, Ju S, Roodman DG, Windle JJ, Zhang X and Lu B: Autophagy promotes T-cell survival through degradation of proteins of the cell death machinery. Cell Death Differ 19: 144-152, 2012.

49. Valdor R and Macian F: Autophagy and the regulation of the immune response. Pharmacol Res 66: 475-483, 2012. 